
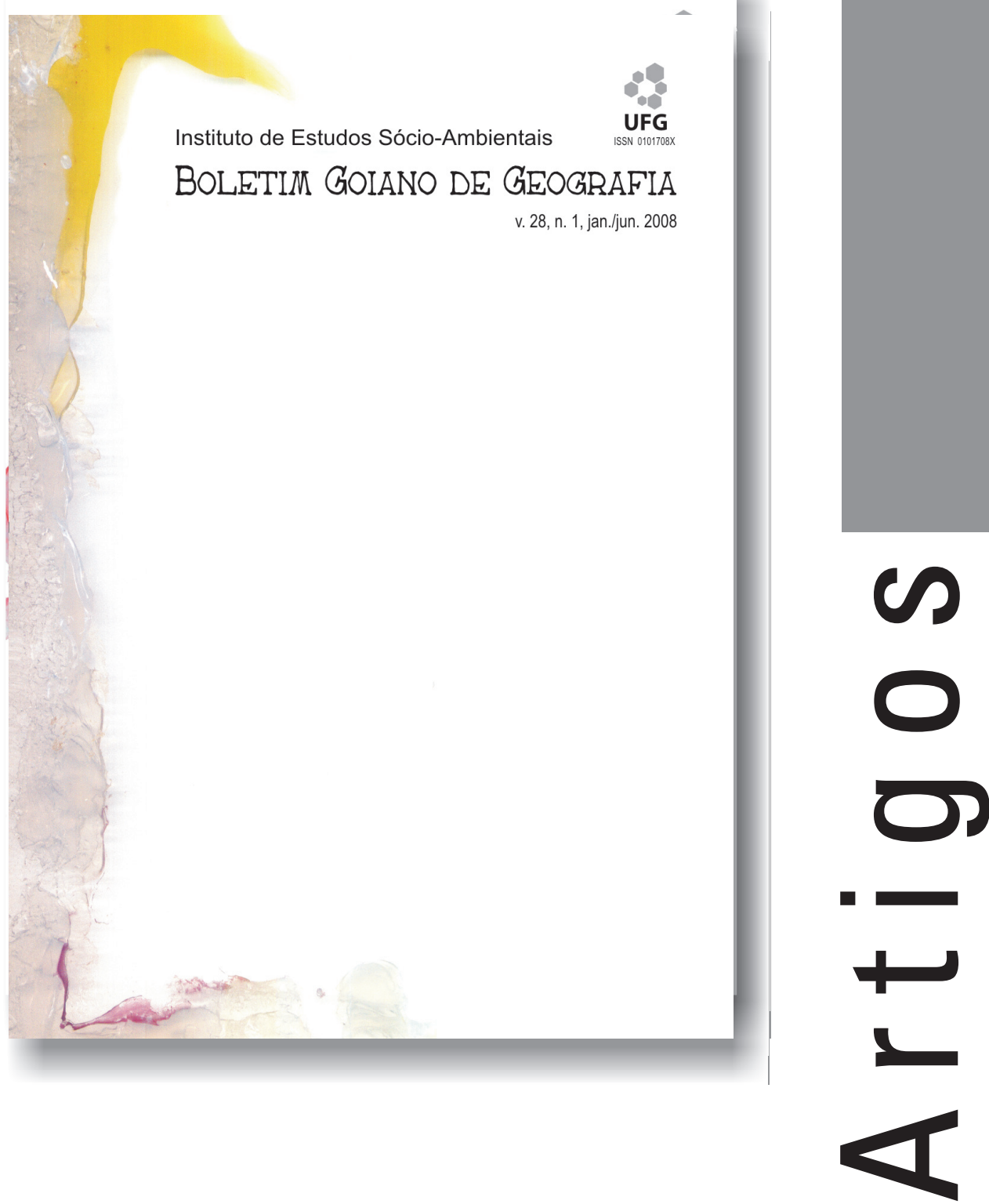


\title{
Patrimônios goianos: intervalos entre a roça e a cidade
}

\author{
Patrimonios goianos: intervalos entre el campo y la ciudad
}

Rusvênia Luiza B. Rodrigues da Silva - Universidade Federal do Tocantins

rusvenia@gmail.com

\section{Resumo}

Este trabalho se vincula à pesquisa de doutorado que vem sendo realizada em duas vilas rurais no interior de Goiás, Cibele e Caiçara. No que se alude à produção espacial, ambas estão influenciadas pelos aspectos da formação da Região do Mato Grosso Goiano que foi ocupada por grandes investidores: "uma nova sociedade rural de fazendeiros e agricultores", conforme confirmou estudo de Brandão $(1985$, p.86). Trata-se de uma área cuja promessa de fertilidade estava amplamente difundida nos discursos dos governos federal e estadual e que por tal fato atraiu grupamentos camponeses do Estado de Minas Gerais e do interior de Goiás, cujo processo de migração ocorreu ao longo das décadas de 1940, 1950 e 1960. São populações de famílias de pequenos exproprietários e de não-proprietários de terra, sendo por tal fato "mais móveis"; gerações inteiras de agregados de fazenda os quais viveram, durante toda a vida, como meeiros e arrendatários. São comunidades guardadoras de saberes que sobejam elementos míticos da fertilidade/fartura/fortuna camponesas, escassos, em constante contradição. Assim, ficam a meio do caminho de um processo que se realiza mas que não extingue as possibilidades de recriação do modo de vida camponês.

Palavras-chave: vilas-rurais, urbanidade, ruralidade, modo de vida camponês

\section{Resumen}

Este trabajo hace parte de una encuesta del doctorado que es realizada, del punto de vista etnográfico más cercano, en dos povoados campencinos en el interior de Goiás, Cibele y Caiçara. En lo que se dice de la producción espacial las dos están influenciadas por los aspectos de la formación de la Región del Mato Grosso Goiano que fue ocupada por grandes investidotes "una nueva sociedad campecina de hacienderos y agricultores" según dice la encuesta de Brandão (1985, p. 86). Eso es una area cuya promesa de fertilización estaba largamente pregonada en las hablas de los goviernos federales y estaduales y que por tal hecho se traje una gran cantidad de campecinos del Estado de Minas Gerais y del interior de Goiás cuyos procesos de migración se pasó a lo largo de las décadas de 1940 y 1960 . Son poblaciones de famílias de pequeños ex dueños y de no dueños e tierra, ya que por tal hecho "más móbiles"; generaciones enteras de los miembros de hacienda, los cuales vivieron durante toda la vida, medianos y alquilantes. Son pueblos dueños de cocimientos que aparten de lo místico de la fertilidad/abundancia/riqueza campencinas, ya inexistentes, en canstante contradición. Así, se quedan en médio del camino de un proceso que se realiza pero que no extingue las posibilidades de recrianza de la manera de la vida del campesino.

Palabras-clave: pueblos campecinos, urbanidad, ruralidad, la manera de la vivenvia del campencino

\begin{tabular}{|l|c|c|c|c|c|c|}
\hline Boletim Goiano de Geografia & Goiânia - Goiás - Brasil & v. 28 & n. 1 & p. 81-98 & jan. / jun. & 2008 \\
\hline
\end{tabular}




\section{Introdução}

Nosso pensamento se situa no desvendamento dos conteúdos presentes nas pequenas cidades do interior goiano e em suas condições de existência a partir do exemplo empírico de duas vilas: Cibele e Caiçara. Interpretamos o lugar considerando uma sincronia espaço-temporal, na qual o tempo se torna dimensão da mudança e o espaço dimensão do social, a coexistência contemporânea de diferenças formuladas pela formação sócio-espacial específica. É profícua a idéia de situação geográfica para sustentar este debate.

O surgimento de Cibele e Caiçara está associado diretamente ao processo migratório de ocupação da região do Mato Grosso Goiano, assim como a mudança do caráter produtivo da fazenda goiana e seu significativo esvaziamento verificado a partir dos anos 1940 e 1950. Este período corresponde a uma transição marcada pela expansão da frente pioneira e a expansão da lógica da economia de mercado. A construção de Goiânia e a abertura de estradas, interligando as principais regiões do Estado à nova capital, foram de suma importância para formação de um mercado regional (Marques, 2000, p. 37).

A conseqüência deste processo foi o esvaziamento das fazendas e o adensamento das vilas que deixam de ser espaços de assistência escolar, religiosa e comercial, e passam a ser moradia das famílias de ex-agregados. Pensar as vilas e a dificuldade de entender essa situação geográfica complexa - o meio do caminho entre a roça e a cidade - é, antes de tudo, fazer um exame dos sentidos que esses lugares recebem: patrimônios sociogeográficos, de tendências contraditórias, fundidas num lugar.

\section{Cibele e Caiçara: entre a serra e o vale}

Enxertados entre a Serra Dourada e o Vale do São Patrício situam-se Cibele e Caiçara, distritos do interior de Goiás, cujas vilas de mesmo nome são objeto de estudo do trabalho de que deriva este artigo. Não se chega a Cibele senão por estradas de terra, havendo vários caminhos que convergem para a vila. Muitos desses acessos tiveram seu momento dinâmico no passado, e hoje se apagaram, empoeirados e abandonados.

A circulação de pessoas circunscreve-se à coleta de leite, atividades de lazer em feriados e finais de semana (em chácaras e fazendas do entorno), e deslocamentos convencionais, que constituem a vida ordinária dos mo- 
radores desses lugares. O principal e mais utilizado acesso a Cibele é uma estrada de terra inominada, trecho de $23,56 \mathrm{~km}$, a partir do primeiro entroncamento da rodovia pavimentada GO 230, iniciada no trevo de Itapuranga, sua sede municipal. Em posição geográfica aparentemente oposta, Caiçara convive, diariamente, com o fluxo de veículos que circula pela rodovia GO 230, cortando a vila de "beira de estrada". O acesso ao município de Faina, sua sede, compreende $31,9 \mathrm{~km}$, pelas GO 230 (trecho não pavimentado) e GO 164 (pavimentada) como demonstra a Figura 1.

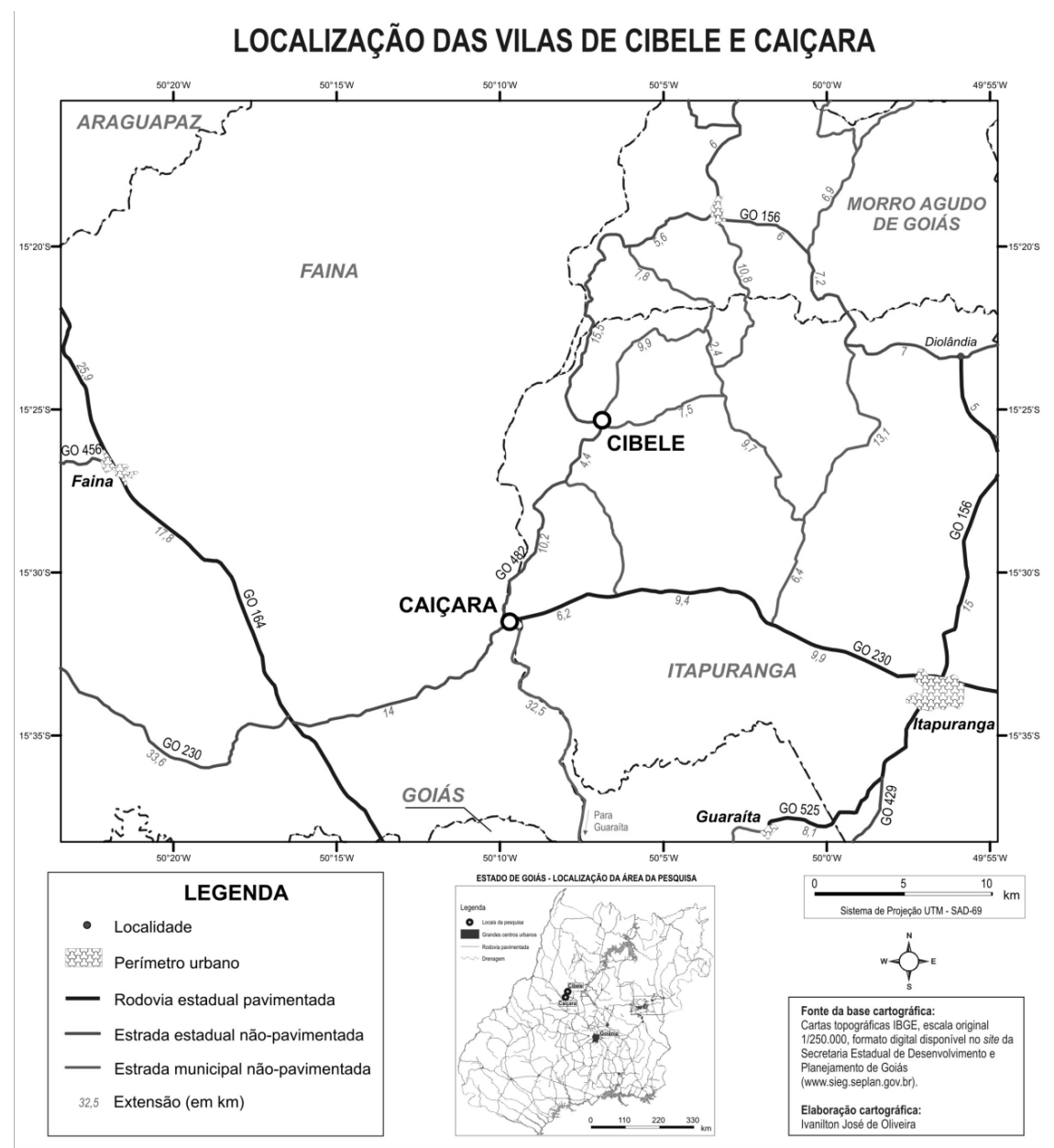

Figura 1 - Mapa de localização das vilas de Cibele e Caiçara. 
O trecho da GO 230 após o trevo do município de Itapuranga, em direção às vilas, não possui muitos moradores, nem postos de gasolina, borracharias ou lanchonetes, infra-estruturas tão comuns em eixos de deslocamentos, mesmo os intermunicipais. Predomina uma paisagem de pastagem, feixes de matas nativas, pequenas roças consorciadas a casinhas pobres e, nos últimos três anos, plantações de eucaliptos e cana-de-açúcar. As lavouras de cana-de-açúcar aos poucos se assentam nesta região, modificando os caminhos do interior de Goiás, com a instalação progressiva de usinas. Qualquer assistência ao viajante é limitada nesta fração da rodovia.

Estradas quase sempre vazias foram uma companhia constante nos períodos das viagens de campo. As placas de sinalização em todo trajeto da GO 230 não informam o acesso a Cibele, mas apenas a Caiçara. A entrada desta vila possui a presença retumbante da igreja católica, como se anunciasse certa hegemonia deste tipo de fé cristã no lugar. A supremacia da fé católica foi reforçada na falas dos muitos informantes caiçarenses, mesmo os de outras filiações religiosas. A igreja é a primeira visão da vila de Caiçara, com uma praça arborizada e um cruzeiro defronte.

Cibele foi, inicialmente, considerada uma "vila-de-fim-de-linha" uma vez que todos os seus acessos são por "leito natural”, seja a partir do trevo de Itapuranga via GO 230 - onde dois entroncamentos direcionam-se àquela vila -, ou a partir da vila de Caiçara, pela GO 482, também não pavimentada, de onde se percorre 14,57 km. A placa informativa que indica Cibele só aparece numa das entradas dos entroncamentos.

A estrada de terra que acessa Cibele foi, muitas vezes, reformada pelos moradores, ainda mais no "tempo das chuvas", quando muitos rios transbordam e destroem parte dela, assim como as pontes do caminho. A vila não é local de passagem ou de acesso inadvertido. Quem trafega por estes caminhos, ou está indo para Cibele, ou para sítios e fazendas do entorno, pois qualquer deslocamento para municípios vizinhos é mais bem acessado por outras rodovias. Já Caiçara é área de passagem para quem se desloca da GO 230 em direção aos municípios e fazendas do Noroeste Goiano. Esta condição geográfica diferenciada não é privilégio de Cibele ou de Caiçara. Outro estudo sobre as vilas, útil para compreensão dessa materialidade intensa e lenta, feito por Araújo (2006, p. 11), iniciou-se assim:

Quem passa pelo interior de Goiás, mesmo que inadvertidamente, não pode deixar de observar perto das estradas asfaltadas pequenas vias de acesso a grupos de casinhas cercadas de roças e até mesmo com algum comércio, um centro de oração, capela ou igreja evangélica. São chamados de vilarejos e na classificação do Instituto Brasileiro de Geografia e Estatística (IBGE), distritos. 
O aspecto envelhecido presente na arquitetura das casas de comércio, muitas delas caiadas de um pálido branco-azulado; o desenho sugestivo das igrejas, confundindo a orientação da fé; as ruínas das delegacias; o abatimento das casas de morar; os acessos abandonados e a decadência das parcas instalações pública; demonstram ser esses "lugares de materialidade lenta", diferentes de muitas cidades contemporâneas de Brasil Central, constituídas com um "piscar de olhos", "cidades-sem-infância". A situação geográfica diferenciada de Cibele e Caiçara indicou, em preâmbulo, a possibilidade de um estudo comparativo entre as duas vilas. Boas (2004, p. 33-34) apresentou as limitações deste tipo de estudo - com ênfase na Antropologia, polemizando sobre o determinismo geográfico e ambiental -, ressaltando os perigos existentes quando se busca o estabelecimento de analogias:

Não se pode dizer que a ocorrência do mesmo fenômeno sempre se deve às mesmas causas, nem que ela prove que a mente humana obedece às mesmas leis em todos os lugares. Temos que exigir que as causas a partir das quais o fenômeno se desenvolveu sejam investigadas, e que as comparações se restrinjam àqueles fenômenos que se provem ser efeitos das mesmas causas. (...) Parece necessário dizer que algo em relação a uma objeção a meus argumentos, que será levantada por pesquisadores que defendem a similaridade de ambiente geográfico como causa suficiente para a similaridade cultural - o que valeria dizer, por exemplo, que as condições geográficas de uma bacia do Missisipi tornam inevitável o desenvolvimento de uma determinada cultura. (Grifo nossos).

A relação entre situação geográfica e desenvolvimento cultural foi amplamente discutida nos estudos da Antropologia com ênfase na busca de padronizações, analogias, definições de traços culturais e outras evidências que apontassem "níveis de desenvolvimento" dos grupos sociais, conforme uma série de exemplos sugeridos por Franz Boas (2004). No caso de um estudo de bases geográficas, o "isolamento" espacial visível de Cibele se deu a partir de processos históricos claramente verificáveis: não é uma conformação espacial isolada para "preservar" um ambiente cultural, mas a perda do dinamismo da região em que a vila está incrustada, a qual, aos poucos, deixa de ser entroncamento de caminhos vitais entre fazendas, pousos e outras vilas do passado. Esses caminhos nunca se pavimentaram "isolando" a vila pela natureza dos acessos e a ausência das funções por ela realizadas no passado.

A constituição de eixos de comunicação dinâmicos que surgem e se apagam e a materialização lenta que torna possível as vilas de beiras-deestrada e de fim-de-linha direcionam o olhar para as diferenças entre essas 
situações geográficas. Apesar de aparentemente integrada e facilmente acessada, Caiçara se "isola" com o final da pavimentação da GO 230, o início do Noroeste Goiano - considerando especificamente esse acesso -, região que, conforme já elucidado, não se caracteriza por atividades que exigem uma dinâmica rodoviária ${ }^{1}$. Assim, verifica-se um duplo isolamento: de sitio (Cibele) e de situação (Caiçara). Esta discussão comparece em Silveira (1999, p. 22-27):

Uma situação geográfica supõe uma localização material e relacional (sítio e situação), mas vai além porque conduz à pergunta pela coisa que inclui o momento da sua construção e seu movimento histórico. (...) Os eventos criam, de um lado, uma continuidade temporal, susceptível de ser cindida em períodos significativos e, de outro, uma coerência espacial que é dada pelos sistemas de eventos nos lugares.

A idéia de situação geográfica é considerada com objetivo de entender as mediações entre o lugar e o mundo que o envolve, os conteúdos das vidas dos moradores interseccionados por acontecimentos e referências em várias escalas: municipais, regionais e mundiais. Considerando o tratamento clássico da análise situacional, quando a idéia de situação esteve associada à posição (proximidade e periferia em relação ao mercado) buscar-se -á associála à perspectiva indicada por Silveira (1999), partindo da identificação da situação para elaboração de um "retrato dos lugares na história do presente". Propor explicar a situação geográfica e a constituição de uma materialidade lenta e precisa é o mesmo que relacionar processo histórico e as múltiplas temporalidades que constituíram os lugares. É preciso seguir o conselho de Santos (1996, p. 63) quando ele diz ser ncessário "buscarmos as categorias analíticas que permitam rever o todo como realidade e como processo, como situação e como movimento”.

\section{Cidades-patrimônio: o meio do caminho}

Propondo uma síntese do desenvolvimento do espaço "urbano” goiano, Chaul e Duarte (2004, p. 12) dividem a existência de nossas cidades em três fases: $1^{\mathrm{a}}$. a cidade-ouro (ou arraiais); $2^{\mathrm{a}}$. a cidade-patrimônio (povoados ou vilas da pecuária, da agricultura e da cultura rústica), e $3^{\mathrm{a}}$ a cidade planejada. O momento de recrudescimento da "cidade-patrimônio" associa-se ao desenvolvimento das atividades agropecuárias em Goiás, vinculadas ao mercado nacional, as que modificaram o papel da Fazenda Goiana. As cidades-patrimônio, ou simplesmente vilas, foram criadas por um fazendeiro, 
quando não, sustentadas ou mantidas pela influência e necessidade de um conjunto de fazendas. Marx (1980, p. 31) aponta as dificuldades na definição dos limites das vilas, relacionadas à proximidade do espaço rural circundante, assim também, por causa dos mecanismos estabelecidos pela Coroa para distribuição e concessão de terras públicas. Sobre a transição arraial - vila, o autor diz:

Os arraiais setecentistas mineiros, de sua parte, se fixavam ombro a ombro com as lavras do ouro e das pedras das alterosas gerais. A arrancada oitocentista do café para o oeste gerou patrimônios agrícolas e aglomerados urbanos em paragens muito diversas. E, finalmente, outra implantação tiveram as novas capitais contemporâneas, como a goiana.

Tardiamente associadas ao desígnio urbano, as vilas marcaram uma transição no abrigo das funções administrativas e da forma urbana, preocupações que não existiam nos arraiais. Porém, os traçados urbanos se desenvolveram ao modo tradicional, mantendo irregularidades e contornos indefinidos. De tradição lusitana, como afirmaram separadamente Florestan Fernandes (1975) e Gustavo Coelho (2001), as vilas no Brasil se constituíram relativamente condensadas e altamente dispersas, designando e obedecendo as funções e formas estabelecidas pelo espaço. Para Fernandes (1975, p.47), “a palavra 'vila' e mesmo o conceito de 'cidade' são logo deturpados, aplicando-se a povoações que, na tradição lusitana, seriam 'arraiais', 'vilarinhos', 'aldeias', 'lugarejos"'. A transição da condição de arraiais para vilas não é uma simples conversão lingüística, mas uma conversão de funções e forma urbanas. Porém, a definição de vila carrega a relação com o campo. Com o auxílio do exercício da etimologia, Le Goff $^{2}$ (1998, p. 12) citou:

Não nos esqueçamos de que a palavra "ville”, para designar aquilo que chamamos de cidade, é muito tardia. Até os séculos XI e XII, escreve-se quase que estritamente em latim e, para designar uma cidade, usa-se "civitas", "cite". Ou urbs, a rigor, mas basicamente "civitas”. E, quando as línguas vernáculas aparecem, o termo "cite" vai permanecer por muito tempo. "Ville" se tomará o sentido urbano apenas tardiamente, já que, como você lembrou, antigamente a palavra designava de fato um estabelecimento rural importante. Uma "villa" não deve pensar numa casa de subúrbio atual - é o centro de um grande domínio. (...) Enfim, a villa é um domínio com um prédio principal que pertence ao senhor; em conseqüência, é um centro de poder (...). (op. cit.)

As questões que fundamentam a decadência dos arraiais reaparecem nas descrições feitas sobre a precariedade das estradas. As vilas surgem com completa dependência dos eixos para que seja possível dinamizar a circulação de pessoas e mercadorias. Os antigos caminhos que demandavam Goi- 
ás se constituíam interligando povoados numa enorme rede de picadas e pontes. Por eles passavam as tropas de muares ao longo dos séculos XVII e XIX - acomodando-se em ranchos às quais foram responsáveis pela origem de vilas caracterizadas pela mesma efemeridade, instabilidade e turbulência dos antigos arraiais do ouro, como pesquisou Gumiero (1991, p. 30). Nessas vilas realizavam-se as negociações e gambiras, termo muito comum para falar das relações comerciais realizadas na época.

Conforme Franco (1997, p. 72), muitos tropeiros tornaram-se, com o passar do tempo, "camaradas de fazenda", enquanto outros, ajudados por suas funções de abastecimento das propriedades e de pequenos comércios interioranos, tiveram outras possibilidades de integração junto ao "outro lado da sociedade", auxiliados pelo aumento das tropas de muares: as riquezas destes homens do sertão. A autora afirma ainda que o tropeiro significou o ponto de articulação entre a tecnologia rudimentar e o grande empreendimento cultural que marcou o percurso do século XIX:

ele aparece como a própria personificação dessas condições objetivas: sua atividade firmou-se por ser indispensável a um momento das operações comerciais, que dependiam, contudo, de um equipamento tecnológico conservado da fase e que a produção tendia para o nível de subsistência (Franco, 1997, p. 66).

O nome comércio foi recorrentemente sugerido como sinônimo de vila e ou de rua nas falas de muitos informantes de Cibele e Caiçara. Os antigos comércios são o elo entre a roça e as mercadorias industrializadas provenientes de áreas longínquas, trazidas nos lombos dos burros. Neles se esboçavam uma estrutura administrativa e um mínimo de intercâmbio com o mundo exterior. Para Walsh (1830) apud Franco (1997, p. 73) "há quatro tipos de pouso encontrados nas estradas do Brasil: o rancho, a venda, a estalagem, a fazenda." Cândido sinalizou (2001, p.76) que o comércio era o lugar, geralmente "pouco habitado, a que vêm ter os moradores da cercania quando precisam de sal, religião ou justiça.” A relação Estado (justiça) e Igreja (religião) é basilar e não deve ser negligenciada: mesmo que não havido uma codificação colonial portuguesa, as normas e procedimentos eclesiásticos eram claramente estabelecidos (Marx, 1991, p.11).

Edificadas por intermédio de uma igreja católica e estabelecida a função comercial, as cidades-patrimônio foram abastecidas com os produtos transportados pela estrada de ferro, conforme Pessoa (1997) ${ }^{3}$. Eram espaços de negociação e gambiragem (atividade de gambira) entre tropeiros, agricultores da migração pioneira, fazendeiros e comerciantes. Aos poucos, algumas cidades patrimônios alcançaram expres- 
são espacial e se tornaram cidades. Outras decaíram, recebendo o estatuto de "cidades mortas" (Ribeiro, 2006, p. 180). Segundo Gumiero (1991, p.57):

Firma o pouso, a palhoça se transformava em rancho, pois surgia nas suas imediações outro morador, que negociava os frutos de sua roça com os tropeiros. $\mathrm{O}$ rancho logo virava povoado, e o povoado prosperava chegando às vezes a vila ou cidade. Em Goiás as cidades de Campo Alegre, antigo arraial Calaça, Piracanjuba (Pouso Alto) e Formosa (Arraial dos Couros) são, entre outros, exemplos de cidades que surgiram de pouso de tropeiros.

Os antigos ranchos de palha - pousos de tropeiros e retireiros; as Casas Comerciais, compondo pequenas aglomerações - "vilarejos estradeiros do interior, do início do século passado" (Ribeiro, 2006, p.180) -, tinham várias funções, tais como: beneficiar culturas produzidas nas redondezas, abrigar um pequeno "grupo escolar", ser o elo entre um e outro povoado, assim como realizar missas e festas religiosas, seguidas do tradicional "pagode”. As condições de trânsito de pessoas entre a fazenda e a vila modulam os "laços de dependência" da existência da vila em relação à fazenda e ao fazendeiro, uma vez que as estradas se abrem, conforme Franco (1997), de acordo com as necessidades da fazenda. Bernardes (1986, p.165) recorda a origem do município de Damolândia em Goiás, que já teve o nome de Capoeirão, derivado da Fazenda do Capoeirão: uma alusão a enorme capoeira encontrada pelos roceiros, desmatada pelos mineiros para constituição da sede da fazenda, em meados de 1912.

Assim como Damolândia, na primeira metade do século XX, intensificaram a formação e o povoamento das cidades em Goiás, estas caracterizadas pelos fluxos da migração pioneira, assim como impulsionadas pela construção da estrada de ferro. Este elemento foi mais intenso nas áreas que receberam diretamente os migrantes do Sul e do Sudeste goianos toda a região do triângulo mineiro e ,mais tarde, o Mato Grosso de Goiás.

Seja como vila, pouso, patrimônio-agrícola, povoados, ou até mesmo comércio, o que caracteriza a existência desses lugares - além da indefinição da nomeação -, é justamente a multiplicidade de funções que se traduzem, a cada tempo, nas diferentes atividades neles exercidas. De certo modo, a convivência entre operações antagônicas: moderno/ rudimentar e exportação /subsistência sempre foi presença constante nestas vilas. A religiosidade, a possibilidade do encontro e o estabelecimento de trocas comerciais e de dádivas existenciais, a realização das festividades, de casamentos, enterros e demais rituais domésticos - íntimos e sociais - coletivos produzem uma dinâmica social que se recria a cada tempo desenhando no espaço estas al- 
terações. É preciso considerar o retorno recorrente à "roça mítica”, tal qual ressaltado por Araújo (2006, p.75), sorvido na presença constante das representações vividas onde a narrativa da memória remete ao passado como um lugar seguro e que sempre retorna, circundando referências e reforçando a posse do presente.

\section{A infância do lugar: Cibele e Caiçara e o eterno-retorno}

Cibele e Caiçara foram dinâmicos espaços de travessia no passado. Povoados constituídos em torno de uma igreja católica - a partir da qual foi fundado o patrimônio, difundido o arruamento, e determinado a dinâmica antiga dos lugares -, guardam em suas ruínas, as recordações de outro tempo, assim também, como nas falas dos moradores, as que permitem caracterizar, semântica e espacialmente, conteúdos contemporâneos elucidativos para o estudo de vilas rurais.

O eterno-retorno ao passado, tantas vezes anunciado nas falas dos moradores das vilas, elucida um sentimento coletivo de saudade. Houve uma significativa mudança no que tange a satisfação das necessidades vitais que diferentes das atuais, eram supridas pela articulação, proximidade e relação com a 'roça' . Nas recordações dos moradores, as vilas possuíam inúmeras casas comerciais: farmácias, lojas de tecidos, máquinas para beneficiar arroz, e açougues. No entanto, não eram espaços de moradia tal qual se configuram atualmente. Porém, tudo o que parecia indispensável à vida estava ao alcance: a igreja para batizar, rezar e casar; o cemitério para enterrar; campo de futebol; cabarés, bares e casas comerciais para diversão, negociações e beneficiamento de culturas. Os laços entre os indivíduos compunham um universo de aparente satisfação e as atividades estavam eminentemente ligadas ao trabalho da família na roça.

Excetuando Cibele, o distrito de Caiçara e os municípios de Itapuranga e Faina foram desmembrados do município de Goiás, antiga capital do Estado. Caiçara é o mais antigo, comparecendo na Comarca de Goiás ${ }^{5}$ no período de 1939 - 1943. Em 1953 registrou-se, na mesma comarca, o distrito de 'Xixá', hoje, Itapuranga (IBGE, 1955). Ambos, Caiçara e Itapuranga, tornaram-se municípios, respectivamente em 1954 e 1953. Em 3/3/1964 foi criado em Caiçara o primeiro Cartório de Ofício do Registro Civil e Tabelionato de Notas, ainda vinculado à jurisdição de Goiás. Em 1988, Caiçara volta à condição de distrito, desta vez, subordinado ao município de Faina que, na 
mesma época, foi desmembrado e emancipado de Goiás. Mesmo assim, a circulação de pessoas é muito mais acentuada em direção a Itapuranga, tanto pela proximidade, quanto pelas características das diferenças de acesso.

A lei municipal de criação do distrito de Cibele é datada de 13/7/1963 e a criação do Cartório de Ofício foi em 4/6/1964, vinculado à Comarca de Itapuranga, município onde o distrito de Cibele esteve assentado. Segundo os moradores mais antigos, a vila já existia quatro anos antes da criação do cartório. Ao fazendeiro José Batista de Faria foi dado o atributo de "fundador do patrimônio, construtor da igreja e do desenho das ruas", conforme vários informantes. A menção à Calango Tonto como nome antigo de Cibele compareceu em duas entrevistas - e foi confirmado em outras tantas -, tendo sido motivado por uma "brincadeira" do fazendeiro-fundador, que pegou um ‘calango' e enfiou pinga em sua goela, tendo o réptil cambaleado ao longo da rua do antigo povoado. Para origem do nome Cibele foram encontradas duas versões, marcadamente defendidas por perfis diferentes de informantes: para os mais novos, a motivação é a origem mítica, associada à fertilidade e a fartura; os mais velhos diziam que era um nome de um "rótulo de goiabada". Apelidos jocosos são freqüentes nas primeiras nomeações de outras vilas goianas, não só da região, podendo ser citado exemplos como: Quiabo Assado (Diolândia), Pendura Saia (Guaraíta), Cavalo Queimado (Araguapaz) entre outros.

Segundo Dona Nenzica, moradora de Caiçara, ela e seu marido foram os que primeiro construíram casas na vila. Por tal fato se autodenominou uma das pioneiras de Caiçara - como fez dona Alice em Cibele, dizendo ser a "mãe" do lugar. Dona Nenzica e outros informantes reafirmaram a figura do fazendeiro Sebastião Xavier como o proprietário de terras que fornecia trabalho e moradia aos roceiros, os quais, posteriormente, construíram suas casas na vila. As entrevistas com os moradores mais antigos foram fundamentais para entender a natureza da ocupação do espaço, na transição de povoado para condição de vila.

Cibele teve como ponto de referência espacial básico, dinâmico e fundamental, a possibilidade de expressão da fé católica, de modo muito simples, num "pequeno ranchinho" aonde se realizou a primeira missa do lugar. Senhor Joaquim, 78 anos, ex-agregado da fazenda Córrego Barreiro, localizada no entorno do distrito de Cibele, relembra o período em que surgiu o patrimônio. 
Aqui, antigamente, por exemplo, era cerradão aqui, não tinha nada, não é? Aí começou, eles compraram aqui e inventaram de surgir, fazer o patrimônio aqui. Foi Zé Batista um homem que morava em Itapuranga [...] ele até já morreu, é o pai do [...] ele se mudou pra cá e compraram aqui do Zé Caiado de Alencar - o pai do Antônio. Aqui ele levantou o Patrimônio, o Zé Batista, não é ? Fez tudo "picadão", as ruas e foi indo assim, fazendo uns ranchinhos, uns e outros ranchos de palha de arroz, pois se colhia muito arroz. Aí, depois, passou muito tempo veio um homem pra cá, que morava em Itapuranga, chamava Bedé, tratavam ele de Bedé baiano. Ele fez uma casinha, um ranchinho ali perto de onde era o posto de telefone antigo. Ali foi a primeira missa celebrada em Cibele, foi na casa desse Bedé baiano. Depois vieram os comércios, uns e outros punham coisinhas pra vender. Passou muito tempo pra chegar a energia motora, a lamparina a diesel ficou um tempão, aí depois ele trousse a energia, fez o posto telefônico e passado uns tempos fez o posto de saúde. O primeiro Grupo ${ }^{6}$ era lá onde hoje é o centro comunitário, depois fez esse grupo aqui no tempo do Otávio [...]. Foi ele que inaugurou esse Grupo, ai foi evoluindo, fez o Grupo, posto telefônico, ai foi surgindo, fez a Igreja Católica, a Igreja Assembléia, a Igreja de Cristo, foi indo assim até o dia de hoje.

Na descrição do informante, a vila passou por 3 momentos:

1. A escolha do sítio: determinado pelo estabelecimento de uma propriedade fundiária e conseqüente definição do traçado das ruas que obedecem ao formato de um 'tabuleiro de xadrez';

2. A construção dos ranchos de palha de arroz: que significa uma relação com a colheita de uma cultura de subsistência - muito provavelmente cultivada pelos agregados das fazendas do entorno da vila - expressando também o caráter 'provisório' das moradias. Os ranchos não eram usados para o estabelecimento do morar, mas para uma visita esporádica, um final de semana de festa, um momento de encontro e até o pouso de viajantes e tropeiros. A realização da missa católica, ainda segundo a narrativa do informante, ocorreu num pequeno rancho coberto de palha de arroz, pois era um importante ingrediente da dieta;

3. A chegada dos 'comércios', da energia elétrica, do grupo escolar e do posto telefônico. A igreja católica ganha uma sede de alvenaria enquanto as construções das igrejas evangélicas ocorrem em período posterior sendo primeiro construída a Assembléia de Deus e depois a Igreja de Cristo.

A primeira missa é sempre recordada quando os informantes narram a fundação das vilas. Antes de se estabelecer um local para realização das missas, há relatos de viagens para lugarejos próximos, assim também para Cruzelândia, nome antigo do município de Morro Agudo de Goiás. Muitas estradas que acessam Cibele e Cai- 
çara são apontadas como caminhos que ligam as vilas à cidade de Morro Agudo ${ }^{7}$. A assistência religiosa provocava a intensificação de deslocamentos tanto na direção de Cruzelândia como também em Itapuranga.

Religião, festa e colheita compunham um universo dinâmico que proporcionava os encontros na vila. As "festinhas", chamadas de pagode, eram bastante animadas e alegres, quando não terminavam em arruaças e contendas. A figura do tocador de sanfona ocupa um lugar de destaque em muitos depoimentos. Dona Alice, anciã de Cibele, diz ter tentado convencer o pai para que permitisse seu namoro com um sanfoneiro, mas foi demovida da intenção, tão logo o pai lhe proferiu a sentença: "tocar sanfona, minha filha, não enche a barriga de ninguém”.

A organização espacial da vila no período 'antigo' revela a coerência da vida social dos sujeitos. Era o lugar que agrupava o disperso: o encontro, a conquista, as contendas e a coesão. Nela aconteciam as festas, os cortejos fúnebres, as negociações, as comemorações, os casamentos. A circulação em torno dos fatos da vida social definia as ruas de maior circulação e importância: por tal fato, verifica-se que os depoimentos dos moradores mais antigos do lugar coadunam-se com as narrativas dos acontecimentos que motivavam a vida no passado.

\section{Considerações finais}

Não é possível separar a conjunção de características que tornam o lugar apreciável, ou mais próximo do sonho de retorno ao passado: a tranqüilidade e o sossego conjugam-se à perspectiva de realização de um cotidiano que nele se desenha. As referências de tempo se dividem e se resumem: o "tempo da roça” e "o tempo de hoje" são oposições que se vinculam às condições materiais de realização da vida um pouco mais "independente" do que parece ser a "cidade grande".

As reações espontâneas e inconscientes, produzidas historicamente, são manifestadas e foram observadas nos trabalhos de campo pela presença de um sentimento intermitente de ausência e de carência. Tais elementos compareceram nos momentos de "descrição" do lugar, bem como no exercício de comparação com outras situações já vividas pelos grupos. Assim, ouviu-se com freqüência: “aqui é quase igual na roça” (mas ser quase igual não é o mesmo que ser igual, então o lugar deixa de ser completamente apro- 
priado... o que o torna "quase" um território); de outro lado, o grupo também admitiu: "aqui talvez não venha ser uma (grande) cidade".

O que faz ser quase são os laços que tornam possível a referência ao passado e que se incluem no plano de uma saudade intermitente, e permite, como que para impedir a sua "morte", um sentimento de continuidade, ainda que "residual": a existência do lugar. A dificuldade dos moradores é a expressão do que falou Martins (2000, p. 22) ao refletir acerca da maneira confusa pela qual a modernidade (e o moderno, em oposição ao tradicional) foi interpretada na América Latina, ressaltando a necessidade de superação que se instaura quando o conflito se torna cotidiano e que:

se dissemina entre valores sociais, de permanente proposição da necessidade de optar entre isto e aquilo, entre o novo e o fugaz, de um lado, e o costumeiro e tradicional, de outro. Porém uma opção esgotada na própria tentativa de optar, pois é opção impossível: o mundo, inclusive o mundo da vida cotidiana, já não é nem uma coisa nem outra, embora pareça ser os dois ou, melhor, os vários e diversos.

Algumas dessas questões, descortinadas ao longo da pesquisa, colocaram-se como elementos significativos para nossas análises. A saudade não é propriamente do trabalho na roça, mas da possibilidade de trabalhar a terra compondo a fartura - no sentido da expressão de uma moralidade camponesa, como apresentou Woortmann (2002, p.12) -, sendo que o significado do trabalho é algo que se herda, um patrimônio. Isto se dá mesmo que o acesso à terra seja mediado pela mudança das fases de incorporação a outras dinâmicas produtivas como a substituição da fazenda que comportava várias famílias de agregados por uma fazenda de poucos peões e conseqüentemente o agrupamento destes camponeses nas vilas rurais.

No plano mais objetivo da ordem social camponesa, o plantio é sempre uma possibilidade de realização da herança, da honra do pai e da família. A análise das mudanças dessas formas de existência, considerando a redução das possibilidades e a recriação do território de vida dos moradores nas vilas rurais é campo profícuo para a representação íntegra dos processos que atravessam, se ajustam e se integram à vida dos sujeitos sociais que moram no interior do Brasil.

Contudo, as vilas rurais são lugares cuja transição inacabada, entre a tradição e a modernidade permite que os fios de transmissão do processo de "modernização" recebam "interferências" e não se realizem por completo, reafirmando e equilibrando valores camponeses ,, "incoerentes” ou "desconexos”, embora recriados, cingidos num mesmo mundo, num mesmo lugar, um Patrimônio. 


\section{Fontes}

1 Segundo Censo Demográfico de 2000 que informa os dados de população e densidade demográfica de Goiás das 18 microrregiões existentes, Ceres (Itapuranga - Cibele) é a $6^{\mathrm{a}}$ em densidade demográfica (212.515) enquanto que Rio Vermelho (Faina - Caiçara) é a $13^{\mathrm{a}}$. Em termos de área o Rio Vermelho é a $11^{\mathrm{a}}$ tendo $20.277,1 \mathrm{Km} 2$ e Ceres a $7^{\mathrm{a}}$ tendo $13.224,4$ Km2. Os dados da SEPLAN sobre a produção agrícola da Região do Rio Vermelho informam que ela está em $15^{\circ}$ lugar no que se refere as principais culturas permanentes e temporárias $\left(0,42 \%\right.$ do Estado) enquanto que Ceres está em $9^{\circ}$ (1,46\%). Situação antagônica ocorre no que se refere aos dados do Rebanho Bovino. A microrregião do Rio Vermelho é o $2^{\mathrm{a}}$ no ranking do Estado, segundo dados da SEPLAN (2003) enquanto Ceres é o $8^{\circ}$.

2 No Por Amor às Cidades - Conversações com Jean Lebrun, Jacques Le Goff se propõe "interrogar a cidade na longa duração" processo que se inicia na Idade Média e se estende nos âmbitos da constituição do poder político, econômico (monetário e financeiro) e que aos poucos se altera provocando uma cidade contemporânea múltipla: algumas demonstram heranças da cidade do passado e outras inauguram um novo modelo, justapondo centros fragmentários (p.143).

3 "Nos pontos terminais da estrada de ferro surgiram várias casas comerciais, que passavam a beneficiar arroz e financiar a produção desse cereal. (...) A expansão da fronteira agrícola nos estados vizinhos à região Sudeste não só era requerida como fonte de produtos primários para o seu abastecimento, mas também como mercado para os produtos de uma indústria emergente" Pessoa (1994, p.35).

4 Utilizo uma idéia de roça não apenas vinculada ao trabalho nos roçados mas as atividades que, em geral, compuseram o trabalho das famílias que moram em Cibele e Caiçara. Numa pesquisa feita com os livros de registro de casamentos dos cartórios de ambas vilas, os homens se identificaram como 'lavradores' e 'roceiros'. O termo 'roça' é muito elucidado ao longo das falas dos informantes das vilas referindo-se ao lugar-roça, a fazenda, ao sítio e a tudo que se coloca como oposição a cidade, inclusive a vila, para o qual usam 'currutela' (corruptela) e, mais freqüentemente, patrimônio.

5 O município de Goiás, onde esteve assentada a antiga capital do Estado, foi instalado em 25 de julho de 1739, quando era composto por 22 distritos (IBGE: 1948, p. 29). Mesmo após a emancipação desses municípios quando o IBGE publicou as Tábuas Itinerárias de Goiás, em 1954, o deslocamento continuava precário. Com a intensificação dos fluxos e a consoante alteração da qualidade e da característica das estradas, possível a partir de uma intervenção mais ativa do Estado, muitos distritos de Goiás, antes "isolados”, elevaram-se à condição de município.

6 A palavra "Grupo" significa, para os informantes o mesmo que "Escola”. O termo é recorrente na fala dos mais velhos.

7 Esbocei no caderno de campo em 23/05/2006: "Parece que todos os caminhos levam a Morro Agudo".

\section{Referências}

ARAÚJO, Maria Emília Carvalho de. Lugar é laço: o saber profundo nas comunidades goianas de Cibele e Caiçara. Goiânia, 2006. 320 f. Tese (Doutorado em Educação) - Faculdade de Educação, Universidade Federal de Goiás. 
BOAS, Franz. Antropologia cultural. Rio de Janeiro: Jorge Zahar, 2004.

BRANDÃO, Carlos R. ; RAMALHO, José Ricardo. Campesinato Goiano. Goiânia: Editora da UFG, 1985.

CÂNDIDO, Antônio. Os Parceiros do Rio Bonito: estudo sobre o caipira e a transformação dos seus meios de vida. São Paulo: Duas Cidades; 34, 2001.

CHAUL, N. N. F. ; DUARTE, L. S. As cidades dos sonhos: desenvolvimento urbano em Goiás. Goiânia: Editora UFG, 2004.

COELHO, G. N. O espaço urbano em Vila Boa: entre o erudito e o vernacular. Goiânia: Editora UCG, 2001.

FERNANDES, Florestan. Comunidade e sociedade no Brasil: leituras básicas de introdução ao estudo macro-sociológico do Brasil. 2. ed. São Paulo: Companhia Editora Nacional, 1975.

FRANCO, Maria Sylvia de C. Homens livres na ordem escravocrata. 4. ed. São Paulo: UNESP, 1997.

GUMIERO, Maristela P. da Paz. Os tropeiros na História de Goiás - Séculos XVIII e XIX. Goiânia, 1991. 109 f. Dissertação (Mestrado em História) - Faculdade de Filosofia e Ciências Humanas, Universidade Federal de Goiás.

IBGE, Censos: Tábuas Itinerárias de Goiás. Rio de Janeiro: IBGE, 1955.

LE GOFF, Jacques. Por amor as cidades. São Paulo, Editora da UNESP, 1988.

MARQUES, Marta Inês Medeiros. De sem-terra a "posseiro", a luta pela terra e a construção do território camponês no espaço da reforma agrária: o caso dos assentados nas fazendas de Retiro e Velha - GO. São Paulo, 2000. 240 f. Tese (Doutorado em Geografia), Faculdade de Filosofia, Letras e Ciências Humanas, Universidade de São Paulo.

MARTINS, José de Souza . A sociabilidade do homem simples. São Paulo: Hucitec, 2000.

MARX, Murillo. Cidade brasileira. São Paulo: Melhoramentos / EDUSP, 1980.

MARX, Murillo. Cidade no Brasil: terra de quem? São Paulo: Nobel / EDUSP, 1991.

PESSOA, Jadir de Moraes. A revanche camponesa: cotidiano e história em Assentamentos de Goiás. Campinas, 1997. 325 f. Tese (Doutorado em Ciências Sociais) - Instituto de Filosofia e Ciências Humanas, Universidade Estadual de Campinas.

RIBEIRO, Darcy. O povo brasileiro. São Paulo: Companhia das Letras, 2006.

SILVEIRA, Maria Laura. Uma situação geográfica: do método a metodologia. Revista Território, ano IV, n. 6, jan-jun. 1999.

WOORTMANN, K. Com parente não se neguceia: o campesinato como ordem moral. Anuário Antropológico, n. 87, p. 11-73. Brasília/Rio de Janeiro, 1990.

Rusvênia Luiza B. Rodrigues da Silva - Professora Assistente do Curso de Geografia da Universidade Federal do Tocantins e doutoranda em Geografia Humana pela Universidade de São Paulo 